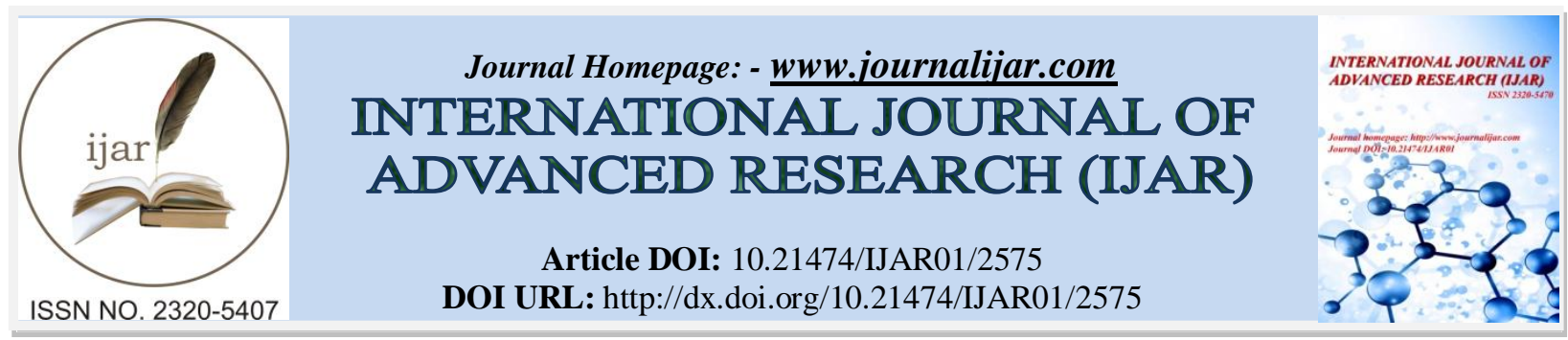

RESEARCH ARTICLE

\title{
INCIDENCE OF PERICORONITIS AND IMPACTED 3RD MOLAR IN PREGNANT PATIENTS VISITING DENTAL OPD.
}

Dr. Richik Tripathi.

BDS, MDS(Oral \& maxillofacial surgery), PhD Scholar faculty of dental sciences , IMS, BHU, VARANASI , INDIA, 221005.

\section{Manuscript Info}

Manuscript History

Received: 27 October 2016

Final Accepted: 25 November 2016

Published: December 2016

\section{Abstract}

Impaction of mandibular and maxillary third molar is usually caused by either due to insufficient maxillofacial skeletal development or due to low correlation between maxillofacial skeletal development and eruption of third molar which leads to lack of space between the second molar and the ramus. Incidence of third molar impaction has increased greatly in past 15 years. Pericoronitis in pregnancy is increasingly evident and preventive and managing steps are required to prevent its occurrence in pregnancy as it can complicate pregnancy and can cause severe oral discomfort. The present paper is aimed to find incidence of such pregnant patients suffering from pericoronitis. In this study 100 female pregnant patients were selected randomly from dental OPD and observed for oral hygiene, missing tooth and pericoronitis. Out of 100 pregnant patients visiting dental OPD 32 patients were found to have pericoronitis and impacted 3rd molar. overall percentage of pericoronitis in study group was $32 \%$. Highest incidence of pericoronitis was found in patients in 3rd trimester of pregnancy and in the age group of 21 to 30 yrs.

Copy Right, IJAR, 2016,. All rights reserved.

\section{Introduction:-}

Impaction of mandibular and maxillary third molar is usually caused by either due to insufficient maxillofacial skeletal development or due to low correlation between maxillofacial skeletal development and eruption of third molar which leads to lack of space between the second molar and the ramus. Incidence of third molar impaction has increased greatly in past 15 years. The modern civilisation have higher incidence of tooth impaction compared to primitive races. It has been postulated that, there is a direct correlation between modern diet and incidence of tooth impaction. The modern diet is more refined and soft compared to traditional and ancient foods. Thus the need of chewing and grinding the food through teeth has greatly decreased and due to evolution the jaws of modern man are getting smaller in size compared to primitive man.

This is assumed to be main reason for tooth size and arch length deficiency and impaction of third molar. Impaction can occur at different angulations and positions in maxilla and mandible. A patient may have one or more impacted tooth in either jaws. Tooth impaction can be diagnosed or identified using clinical or radiological methods. If tooth is impacted partially it can be identified clinically however full bony or soft tissue impactions can be identified through radiological methods which include, orthopantomograph, lateral oblique view and intra oral periapical view. Incidence of mandibular third molar impaction is highest followed by by maxillary third molars, 
maxillary canines and mandibular canines. Maxillary or mandibular third molars are last teeth to erupt in oral cavity and the chances for getting impacted are comparatively high with respect to other teeth in oral cavity ${ }^{1}$.

Discrepancy between the size of third molar and available arch length is believed to be a major contributing factor for tooth impaction which can be attributed to many factors which include, soft diet, insufficient eruption forces and hereditary factors.

Mesioangular impaction is the most common type of mandibular third molar impaction and vertical impaction is most common type of maxillary third molar impaction. Incidence of third molar impaction in mandible ranges from 9.5 to $50 \%^{1,2}$ and in maxilla it ranges from 8 to $39 \% \%^{1,2}$

Impacted tooth should be differentiated from embedded tooth in which there is lack of eruption forces ${ }^{3}$ while in impacted tooth, the tooth is prevented from getting erupted due to lack of space or some physical barrier ${ }^{4}$.

\section{Gender distribution:-}

There seems to be a sexual predilection in third molar impaction pattern ${ }^{1,5}$. It has been found in several studies that, impacted third molars are more common in females compared to males ${ }^{5}$.

During pregnancy there is significant changes in systemic and oral regions of body. The estrogens and progesterone hormone level during pregnancy are 3 to 4 fold high which greatly accelerates the response of oral mucosa to inflammatory agents. The normal oral microbial flora in pregnancy is disturbed and there is significant increase in proportion of anaerobic to aerobic bacteria. Pericoronitis in pregnancy is increasingly evident and preventive and managing steps are required to prevent its occurrence in pregnancy as it can complicate pregnancy and can cause severe oral discomfort. The present paper is aimed to find incidence of such pregnant patients suffering from pericoronitis.

\section{Aim and Objectives:-}

To find the incidence of pericoronitis and impacted third molar in pregnant patients visiting dental OPD for dental consultation.

\section{Materials and methods:-}

100 female pregnant patients were selected randomly from dental OPD and observed for oral hygiene, missing tooth and pericoronitis.

\section{Inclusion criteria:-}

1. Presence of pregnancy

2. Presence of pericoronitis

3. age < 35yrs

4. absence of any other odontogenic infections

5. Good general health

6. absence of genetic or birth defects affecting growth of mandible, maxilla

\section{Exclusion criteria:-}

1. Severe odontogenic infections

2. patients with positive medical history

3. Surrogate mothers

Patients who met the inclusion criteria were included in study group and stage of pregnancy and type of impaction was classified. Average incidence of pericoronitis was calculated by dividing the number of identified cases with number of total cases of pregnant patients visiting dental opd. The identified cases were further divided into subgroups depending upon age, type and stage of pregnancy. For classifying type of impaction, line along the long axis of 3rd and 2nd molar was drawn and angle between them was measured and they were classified as
A. Vertical
$\left(0^{\circ}\right.$ to $\left.10^{\circ}\right)$
b. Mesioangular
$\left(11^{\circ}\right.$ to $\left.79^{\circ}\right)$
c. Horizontal
$\left(80^{\circ}\right.$ to $\left.100^{\circ}\right)$
d. Distoangular
$\left(-11^{\circ}\right.$ to $\left.-79^{\circ}\right)$ 

e. Others
$\left(-111^{\circ}\right.$ to $\left.-80^{\circ}\right)(\text { Quek et al } 2003)^{5}$

\section{Results:-}

Out of 100 pregnant patients visiting dental opd 32 patients were found to have pericoronitis and impacted 3rd molar. overall percentage of pericoronitis in study group was $32 \%$ (Graph 1)

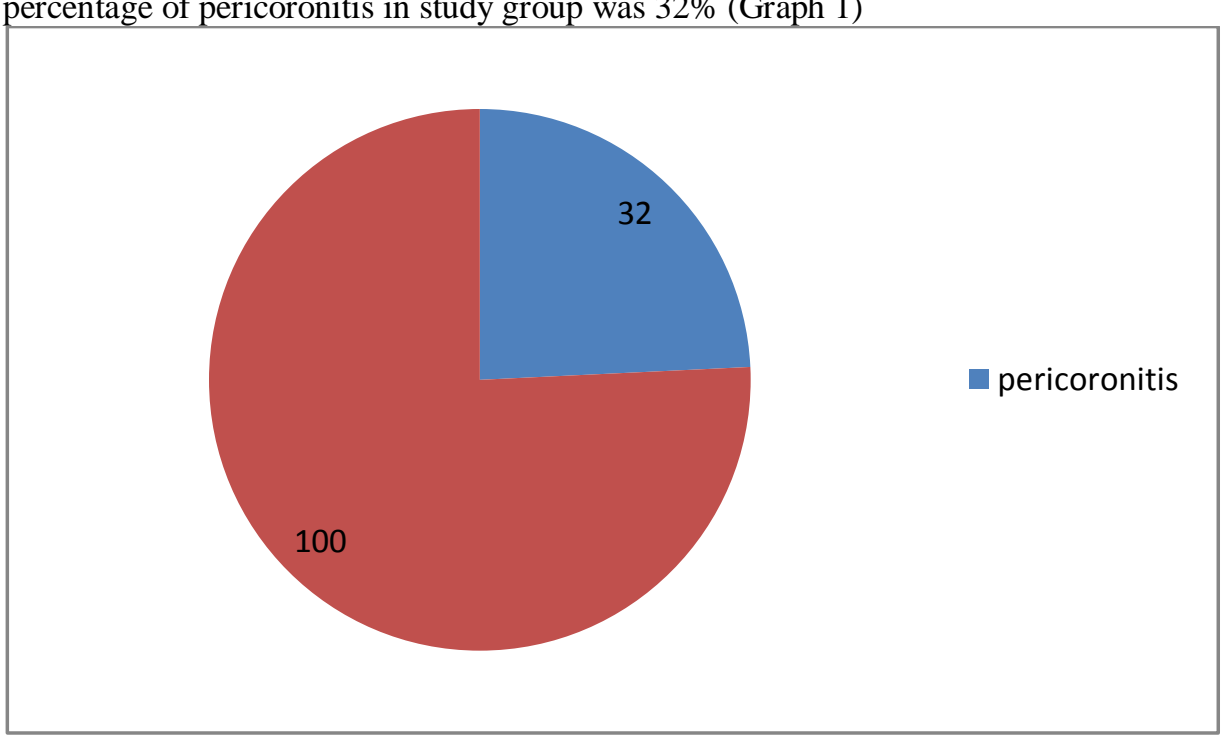

Graph 1:- showing incidence of pericoronitis in pregnant patients.

3 patients were in age range of 18 to 20 years. 18 were in age range of 21-30 years and 11 were in age range of 31$40 \mathrm{yrs}($ table -1$)$. pericoronitis was highest in age group of 21 to 30 years(graph 2)

Table 1:- showing age wise classification of pericoronitis patients in study group.

\begin{tabular}{|c|c|c|}
\hline Age group of patients & Number of patients & percentage \\
\hline $18-20$ years & 3 & $9.3 \%$ \\
\hline $21-30$ years & 18 & $56.2 \%$ \\
\hline $31-40$ years & 11 & $34.5 \%$ \\
\hline
\end{tabular}

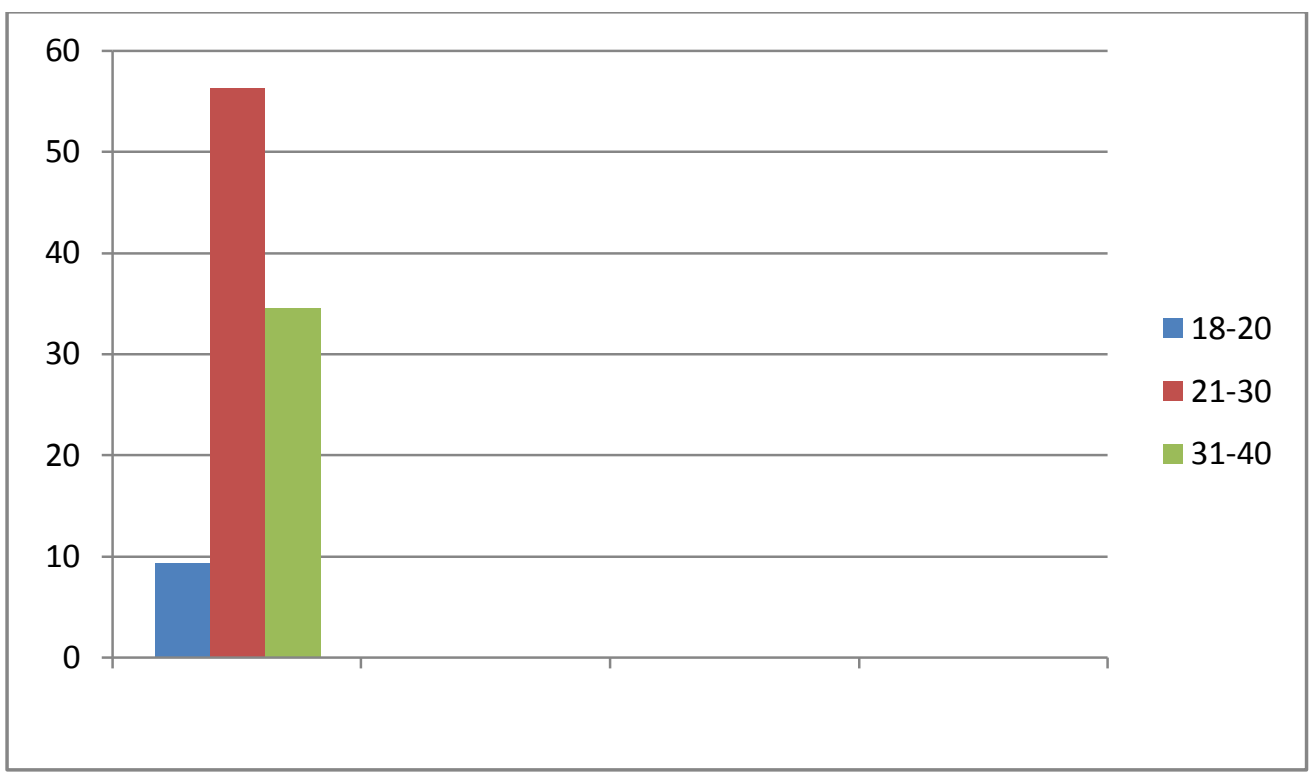

Graph 2:- Showing age wise classification of pregnant patients in study group. age group 21-30 yrs has highest incidence of pericoronitis. 
Table 2:- Showing classification of impaction type in study group .

\begin{tabular}{|c|c|}
\hline Type of impaction & Number of cases \\
\hline Vertical & 5 \\
\hline Horizontal & 4 \\
\hline Mesioangular & 16 \\
\hline Distoangular & 7 \\
\hline
\end{tabular}

mesioangular impaction remained the most common type of impaction in study group followed by distoangular and vertical type(table 2, graph 3 )

\section{classification of impaction types}

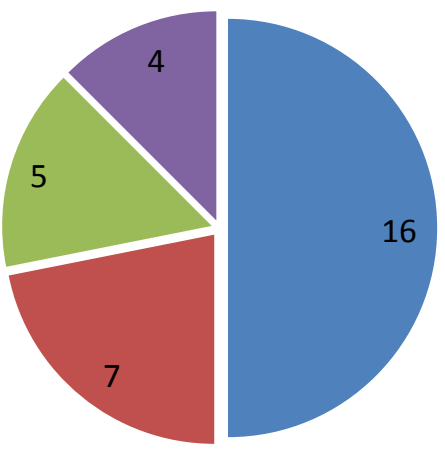

mesioangular

distangular

vertical

horizontal

Graph 3:- showing classification of impaction types in study group

Table 3:- showing classification of pregnancy period in study group

\begin{tabular}{|c|c|c|}
\hline Trimester & No of patients & Percentage \\
\hline 1st & 6 & $18.7 \%$ \\
\hline 2nd & 11 & $34.3 \%$ \\
\hline 3rd & 15 & $47 \%$ \\
\hline
\end{tabular}

Highest incidence of pericoronitis was found in patients in 3rd trimester of pregnancy followed by 2 nd and 1 st trimester(table 3 , Graph 4)

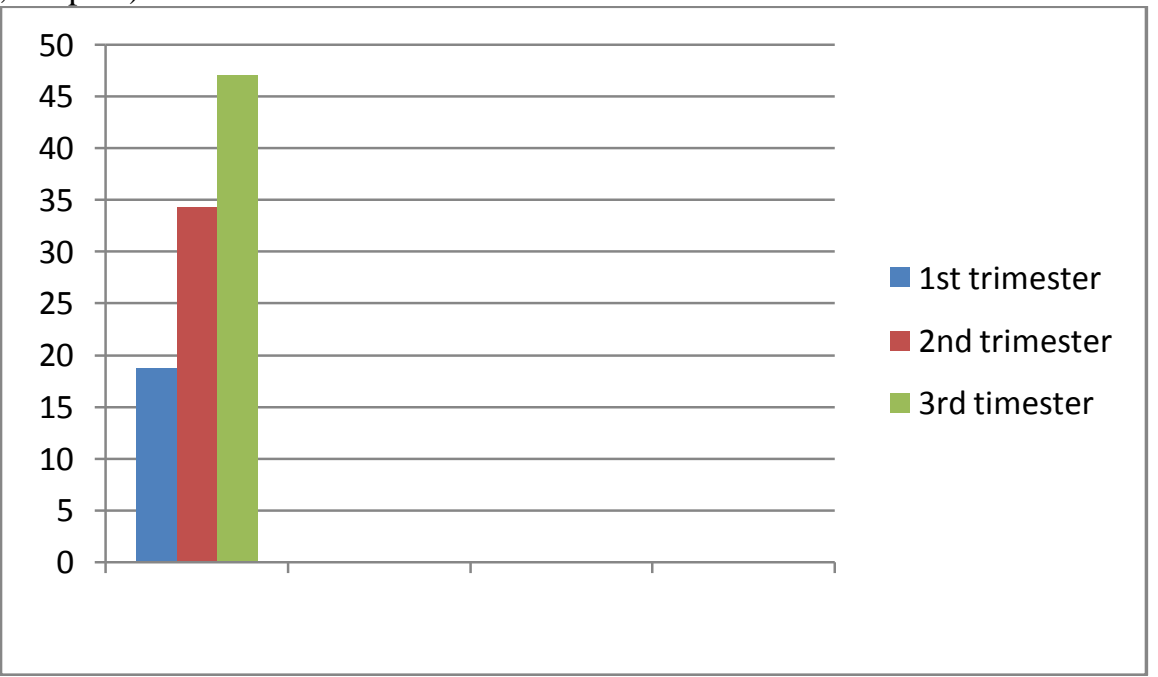

Graph 4:- showing incidence of pericoronitis in relation to timing of pregnancy 


\section{Discussion:-}

Impaction of 3rd molar and pericoronitis is becoming increasingly evident in young population. In pregnancy the level of estrogens and progesterone are three to four fold high ${ }^{6}$ and can augment oral mucosal response to inflammatory stimulus.

Significant changes are seen in oral microflora during pregnancy and under the influence of raised level of estrogen and progesterone, inflammatory conditions or infections can occur anytime ${ }^{7}$. This causes serious oral discomfort and it has negative impact on fetus development ${ }^{8}$. There is a risk of premature labour and low birth weight babies if mother develops inflammation or infection in oral cavity ${ }^{9}$. If antibiotics and anti inflammatory are given during pregnancy, these drugs directly pass through the placenta and can alter proper development of fetus ${ }^{10}$. Drug modification and fetal monitoring is required in such circumstances.

To overcome such situations, detection and extraction of impacted 3rd molar should be made mandatory as a part of oral heath check up programme before pregnancy. In this study the incidence of pericoronitis in pregnant females is $32 \%$ which is much higher than previous studies. The incidence is much higher in age group of 21 to 30 years. Previous studies has nearly same findings. When compared to overall incidence without sex predilection the incidence is highest in age group 21 to 30 years. The most important finding of this study is, a high number of patients with impacted tooth and pericoronitis are in 3rd trimester of pregnancy. It is a well known fact that inflammatory conditions are predisposing factors to low birth weight babies and unexpected delivery. This further complicates the situation of pregnant patient.

\section{Conclusion:-}

Overall incidence of pericoronitis in pregnant patients is $32 \%$. Highest incidence is seen in age group 21 to $30 \mathrm{yrs}$ and in the 3rd trimester of pregnancy.

\section{References:-}

1. Ali H Hassan, Pattern of third molar impaction in a Saudi population, Clin Cosmet Investig Dent. 2010; 2: 109-113.

2. Farman A G, Tooth Eruption and Dental Impactions.. Panoramic Imaging News. 2004; 4 (2): 1-9.

3. Qirreish E J Radiographic profile of symptomatic impacted mandibular third molars in the Western Cape, South Africa. Masters degree dissertation. Western Cape: University of Western Cape.2005

4. Neville BW, Damm DD, Allen CM, Bouquot JE, Oral and maxillofacial pathology. (2002).Philadelphia: Saunders.

5. Quek S L, Tay C K, Tay K H,Toh S L , Pattern of Third Molar Impaction in a Singapore Chinese Population: A Retrospective Radiographic Survey.. International Journal of Oral Maxillofaial Surgery.2003; 32: 548-552

6. Min Wu, Shao-Wu Chen, and Shao-Yun JiangRelationship between Gingival Inflammation and Pregnancy, Mediators Inflamm. 2015; 1:1-11

7. Megan K. Kloetzel, Colleen E. Huebner, and Peter Milgrom J Referrals for Dental Care During Pregnancy Midwifery Womens Health. 2011 Mar; 56(2): 110-117.

8. Kristen S. Marchi, ,Susan A. Fisher-Owens, Jane A. Weintraub, Zhiwei Yu, MPH, and Paula A. Brveman Most Pregnant Women in California Do Not Receive Dental Care: Findings from a Population-Based Study Public Health Rep. 2010 Nov-Dec; 125(6): 831- 842.

9. Elifuraha GS Mumghamba and Karim P Manji, Maternal oral health status and preterm low birth weight at Muhimbili National Hospital, Tanzania: a case-control study BMC Oral Health. 2007; 7: 8

10. Begoña Martinez de Tejada Antibiotic Use and Misuse during Pregnancy and Delivery: Benefits and Risks , Int J Environ Res Public Health. 2014 Aug; 11(8): 7993- 8009 